\title{
Seed Storage Reserves and Glucosinolates in Brassica rapa L. Grown on the International Space Station
}

\author{
M.E. Musgrave ${ }^{1}$ \\ Department of Plant Science, 1376 Storrs Road, Unit 4067, University of Connecticut, Storrs, \\ CT 06269
}

A. Kuang

Department of Biology, University of Texas-Pan American, Edinburg, TX 78541

L.K. Tuominen

Orbital Technologies Corporation, Madison, WI 53717

L.H. Levine

Dynamac Corporation, Kennedy Space Center, FL 32899

\author{
R.C. Morrow \\ Orbital Technologies Corporation, Madison, WI 53717
}

AdDitional INDEX wORDs. spaceflight, microgravity, starch, seed development, embryo

\begin{abstract}
Although plants are envisioned to play a central role in life support systems for future long-duration space travel, plant growth in space has been problematic due to horticultural problems of nutrient delivery and gas resupply posed by the weightless environment. Iterative improvement in hardware designed for growth of plants on orbital platforms now provides confidence that plants can perform well in microgravity, enabling investigation of their nutritional characteristics. Plants of $B$. rapa (cv. Astroplants) were grown in the Biomass Production System on the International Space Station. Flowers were hand-pollinated and seeds were produced prior to harvest at 39 days after planting. The material was frozen or fixed while on orbit and subsequently analyzed in our laboratories. Gross measures of growth, leaf chlorophyll, starch and soluble carbohydrates confirmed comparable performance by the plants in spaceflight and ground control treatments. Analysis of glucosinolate production in the plant stems indicated that 3-butenylglucosinolate concentration was on average $75 \%$ greater in flight samples than in ground control samples. Similarly, the biochemical make-up of immature seeds produced during spaceflight and fixed or frozen while in orbit was significantly different from the ground controls. The immature seeds from the spaceflight treatment had higher concentrations of chlorophyll, starch, and soluble carbohydrates than the ground controls. Seed protein was significantly lower in the spaceflight material. Microscopy of immature seeds fixed in flight showed embryos to be at a range of developmental stages, while the ground control embryos had all reached the premature stage of development. Storage reserve deposition was more advanced in the ground control seeds. The spaceflight environment thus influences $B$. rapa metabolite production in ways that may affect flavor and nutritional quality of potential space produce.
\end{abstract}

Plants are envisioned to play a role in supporting long duration space exploration initiatives. It is estimated that a hydroponic growing area of $20-50 \mathrm{~m}^{2}$ would be able to provide the nutritional needs of one person on a continuing basis [National Research Council (NRC), 1997], using plants specially developed to maximize harvest index and to minimize production time and energy input. At the same time, gas exchange and transpiration by the plants in this growing area would provide two times the $\mathrm{CO}_{2}$ scrubbing and oxygen replenishment needs of the person, and more than four times the water recycling requirements (NRC, 1997). While the potential of plants to serve this role has been

\footnotetext{
Received for publication 8 Feb. 2005. Accepted for publication 28 Apr. 2005. Supported by NASA grants NAG10-329, NAG2-1375, and Orbitec contracts to MEM and AK. LKT gratefully acknowledges the Marine Biological Laboratory's NASA Planetary Biology Internship Program and her sponsor at Kennedy Space Center, Raymond Wheeler. The assistance of Astronaut Dan Bursch with inflight operations on the International Space Station and David Chapman with groundcontrol operations at Kennedy Space Center, is greatly appreciated.

${ }^{1}$ To whom reprint requests should be addressed;

Email address: mary.musgrave@uconn.edu
}

established by extensive ground-based testing and modeling, actual data on plant performance in microgravity or reduced gravity are scarce. Acquisition of these data has been hampered by the considerable horticultural challenges surrounding plant growth in microgravity. In particular, fluid behavior, nutrient delivery, and gas resupply within the plant chamber have been critical issues that have required incremental improvements in hardware design (Porterfield et al., 2003).

In Apr. 2002, the Biomass Production System (BPS) was transported to the International Space Station on Space Shuttle Atlantis. As part of a hardware verification test (Morrow et al., 2004), plants of B. rapa 'Astroplants' were grown in one of the hardware's four chambers. Although the goal of the verification test was to put the hardware through its paces and determine performance, this was a unique opportunity to continue our general studies on the growth and development of plants in microgravity. Of special interest was the capability for inflight manipulations over a long-duration mission, making it possible to examine aspects of seed development and secondary metabolism in microgravity that had not been previously studied. In particular, the capability of inflight freezing allowed us to preserve the biochemical state for 
post-flight analyses, while previously work had been confined to using fixed material or tissues harvested postflight. We used this opportunity to assess spaceflight effects on the composition of seed storage reserves during development and on the production and storage of glucosinolates in stem tissue. Other parts of the plants were used to verify that general growth, development and physiology were proceeding as expected in microgravity.

SeEd StORAGe ReSERVES. Brassica (Brassica L. spp.) has been proposed as a candidate crop for a biological life support system because of its value as an edible oil and protein source (Frick et al., 1994). Biochemical analysis of dry seeds from commercial brassica indicates that $\approx 40 \%$ of the dry weight is protein (Robbelen and Thies, 1980). In a previous long-duration experiment on the Mir space station in which we grew B. rapa from seed to seed for multiple generations, starch was retained as a major storage reserve, suggesting significant consequences for the nutritional quality of seeds that would be produced in microgravity (Musgrave et al., 2000). Working with dry seeds that had formed in space, we found that the total size of protein bodies represented $\approx 26 \%$ of the cell in space-produced seeds, compared with $33 \%$ in the ground-produced seeds. Seed weight was significantly reduced by development in microgravity, and as a consequence, so too was the vigor of subsequent generations of plants diminished when seeds had developed in microgravity. These data put into question the application of plants in biological life support scenarios that might be proposed for use in transit vehicles.

In a separate study on the shuttle orbiter Columbia, we produced different aged cohorts of developing $B$. rapa embryos through successive pollination events over a 1 -week period. Preparation of this material for microscopy immediately post-flight and subsequent analyses confirmed a delay in storage reserve deposition in the spaceflight environment (Kuang et al., 2000a, 2005). The present study utilized comparable material that was fixed or frozen while the plants were still in orbit.

GLuCOSINOLATES AND THE SPACEFLIGHT ENVIRONMENT. Glucosinolates ( $\beta$-thioglucoside- $N$-hydroxysulfates) are a class of secondary metabolites found mainly in the order Capparales and co-exist with endogenous thioglucosidases called myrosinases (EC 3.2.3.1). Tissue disruption brings glucosinolates in contact with myrosinases that are otherwise separately compartmentalized, and results in the release of numerous compounds (e.g., isothiocyanates, nitriles, and thiocyanates) with diverse biological activities (Chen and Andreasson, 2001). These degradation products not only account for the distinctive flavors of cabbage $(B$. oleracea L. var. capitata L.) and condiments including white mustard ( $B$. hirta Moench.) and black mustard (B. nigra L.), but also account for the anticarcinogenic properties in brassica vegetables (Fahey et al., 1997; Zhang and Talalay, 1994) as well as goitrogenic properties in rape (B. napus L.) seeds [see Mithen (2001) for a review]. The composition of glucosinolates determines how flavorful and beneficial such vegetables will be. Glucosinolate composition is largely controlled by genetic makeup (Branca et al., 2002) and strongly influenced by developmental stage (Brown et al., 2003; Fahey et al., 2001, 1997; Petersen et al., 2002) and environmental conditions (Champolivier and Merrien, 1996; Ciska et al., 2000; Pereira et al., 2002). However, it is not known whether or how the spaceflight conditions would affect the metabolism of this important class of secondary metabolites. Insight to this question is essential from the perspective of providing astronauts with a more flavorful and functional food with potential as a countermeasure against ionizing radiation. In space, where foods reportedly seem more bland (Olabi et al., 2002), it will be necessary to have levels of flavor and fragrance compounds in foods at least as high as in those grown on Earth. Astronauts are inevitably exposed to a high level of ionizing radiation that results in oxidative stresses and increasing rate of carcinogenesis (Pence and Yang, 2000). Therefore, a diet high in antioxidants (Fang et al., 2002) or anticarcinogenic compounds would be preferred.

\section{Materials and Methods}

Tissue. Brassica rapa 'Astroplants' (CrGC \#1-59; Crucifer Genetics Cooperative, Madison, Wis.) were grown on board the space shuttle orbiter Atlantis and the International Space Station (ISS) in the BPS (Orbital Technologies Corp., Madison, Wis.). The BPS provides regulated nutrient delivery, light, carbon dioxide levels, temperature, and relative humidity to four $16.5-\mathrm{cm}$-long $\times$ 14.7-cm-wide $\times 18.8$-cm-high chambers (for environmental data, which were gathered using custom built hardware, see Table 1). Environmental parameters were measured as follows: light, photodiode (PIN-2PPI; UDT Sensors, Hawthorne, Calif.); root temperature, resistance temperature detector (RTD) probe (EI1502113/F3141/RTD-860/36in; Omega Engineering, Stamford, Conn.); $\mathrm{CO}_{2}$, infrared sensor (GMM11; Vaisala, Helsinki, Finland); rootzone water potential, pressure gauge (MPX 2010; Motorola, Denver); air temperature (RTD) and humidity (capacitance) sensors (HIH3602C; Honeywell, Morristown, N.J.).

Seeds were sown in four rows of 10 seeds in one BPS chamber, and germination was activated on the ground $4 \mathrm{~d}$ prior to the launch of Shuttle Transport System(STS)-110, which transported the BPS to the ISS. Ground control plants were grown in a single chamber of a second BPS unit that had been programmed to replicate environmental conditions of the spaceflight unit and was housed in the Orbiter Environment Simulator (OES) at Kennedy Space Center. There was a 14-d delay between the flight and ground BPS units to allow spaceflight environmental conditions to be programmed into the OES. Plants were pollinated on days 20,22 , and 26 respectively after seeds were planted. On days 13 , 17 , and 19 post-pollination, plants (four plants from the ISS and four from the ground control) with siliques were fixed with $3 \%$ glutaraldehyde in phosphate buffer for examination postflight. Plants in fixative were dissected immediately after receipt in the laboratory at Univ. of Texas-Pan American. The remaining plants were grown for $39 \mathrm{~d}$, after which they were harvested and frozen at $-25^{\circ} \mathrm{C}$ in the ARCTIC (spaceflight hardware) freezer on ISS. Frozen tissue was subsequently transported back to the ground at $-196{ }^{\circ} \mathrm{C}$ in the gaseous $\mathrm{N}_{2}$ freezer. Stem tissue was dissected from major portions of leaf, flower, silique, and root tissue while frozen and set aside for glucosinolate analysis. Leaf tissue was set aside for chlorophyll, starch and soluble carbohydrate analyses. Seeds were dissected from frozen siliques and bulked for subsequent analyses for protein, chlorophyll, starch and soluble carbohydrates. Flight and ground samples were then lyophilized and stored between -20 and $-80{ }^{\circ} \mathrm{C}$.

Microscopy. Embryos dissected from fixed siliques were further processed for light and electron microscopic observation. For scanning electron microscopy, embryos were dehydrated with an ethanol series $(30 \%, 50 \%, 70 \%, 90 \%$, and $100 \%$, v/v ethanol) and critical point dried with liquid $\mathrm{CO}_{2}$. Embryos were then mounted on a metal stub and coated with gold-platinum before examination with a LEO 435VP scanning electron microscope (Carl Zeiss SMT, Thornwood, N.Y.). For light microscopic observation, embryos dehydrated with the ethanol series were then infiltrated with and embedded in L.R. White resin (Electron 
Microscopy Sciences, Fort Washington, Pa.). The embedded embryos were sectioned with a Leica microtome (Leica Mikrosystem Aktiengesellschaft, Wien, Austria) and sections ( $1 \mu \mathrm{m}$ thick) were stained with Periodic Acid Schiff's reagent (Carolina Biological Supply Co., Burlington, N.C.) for carbohydrates and Aniline Blue Black (Carolina Biological) for protein. Stained sections were observed and photographed with an Olympus compound microscope (Olympus Corp., Melville, N.Y.).

Chlorophyll and Storage reserve Determinations. Lyophilized leaf and seed samples were extracted in $80 \%$ ethanol and total chlorophyll determined spectrophotometrically by reading absorbance at 665 and $649 \mathrm{~nm}$. Following chlorophyll determination the samples were further processed according to methods used previously in Stout et al. (2001), to quantify soluble carbohydrates and starch. Seed protein was determined as in Mansfield and Briarty (1996) according to Peterson's modification of the micro-Lowry method using Sigma protein assay kit (P5656; Sigma-Aldrich Corp., St. Louis).

Glucosinolate Analysis. Due to the small quantity of seed available for analysis, glucosinolates were extracted from freezedried stems of both space-grown and ground control plants, partially purified by using an anion exchange resin, and desulphonated according to Kiddle et al. (2001) with the following modifications: 1) Approximately $20 \mathrm{mg}$ lyophilized stem tissue was homogenized with $70 \%$ methanol in a freeze-grinding tube using a freezer mill (model 6750; SPEX CertiPrep, Metuchen, NJ). The homogenate was quantitatively transferred and extracted three times $(2 \times 750 \mu \mathrm{L}$ and $1 \times 500 \mu \mathrm{L})$ by incubating the mixture at $70{ }^{\circ} \mathrm{C}$ for $30 \mathrm{~min} /$ extraction in an Eppendorf Thermomixer (Brinkmann Instrument, Westbury, N.Y.). Ten microliters of $3.00-\mathrm{mg} \cdot \mathrm{mL}^{-1}$ sinigrin was added to the extraction mixture as an internal standard. Extract from all three extractions was pooled. Four such extracts (two to three plants/replicate) were prepared for each experimental treatment. 2) Anion exchange and desulphonation were performed in a 5-mL Centrex MF-5 centrifugal filter unit (Schleicher \& Schuell, Keene, N.H.) with a 0.45- $\mu$ m nylon filter membrane. Each extract was further divided into two equal aliquots, and each mixed with 85 ( \pm 6.0) $\mathrm{mg}$ DEAE Sephadex A-25 (Sigma-Aldrich) pre-swollen in deionized water. After 20 min incubation, unretained compounds and solvent were removed by centrifugation at $2060 g_{\mathrm{n}}$. The resin was washed twice with $800 \mu \mathrm{L} 67 \%$ methanol and once with $800 \mu \mathrm{L}$ deionized water. Subsequently, $15 \mu \mathrm{L}$ of sulfatase solution (3540 units/mL, type H-2 from Helix pomatia L.; Sigma-Aldrich) and $800 \mu \mathrm{L} 20 \mathrm{~mm}$ acetate buffer ( $\mathrm{pH} 5.5$ ) were added to the resin where glucosinolates were bound, and incubated overnight in the dark at room temperature. Desulphonated glucosinolates were eluted with 2 $\times 640 \mu \mathrm{L} 60 \%$ methanol. Eluents were evaporated to dryness in a vortex evaporator under vacuum at $40{ }^{\circ} \mathrm{C}$, then reconstituted in $225 \mu \mathrm{L}$ deionized water. Samples were stored in a $-80{ }^{\circ} \mathrm{C}$ freezer until analysis. Sinigrin standard (five concentrations) was desulphonated in a similar manner to assess the recovery of sample preparation procedure.

Desulphonated glucosinolate preparations and standards were filtered through a $0.45-\mu \mathrm{m}$ syringe filter into silanized high-pressure liquid chromatography (HPLC) vial inserts and analyzed using a HPLC system equipped with a quaternary pump, thermostated autosampler, and photodiode array detector (Thermo Separation Products, San Jose, Calif.). Separation was carried out on a Supelcosil LC-18 column $(250 \times 4.6$ mm, 5 um; Supelco, Bellefonte, Pa.) by injecting $20-\mu \mathrm{L}$ samples using an acetonitrile:water linear gradient at a flow of $1.5 \mathrm{~mL} \cdot \mathrm{min}^{-1}$. The mobile phase composition is $0 \%$ acetonitrile initially, and increases to $40 \%$ at 30 min with a ramping rate of $1.5 \%$ per minute, and holds for $10 \mathrm{~min}$. Signal was recorded at $227 \pm 7 \mathrm{~nm}$. Compounds eluted from the HPLC were also introduced onto an ion trap mass spectrometer (Thermo Finnigan LCQdeca; Thermo Electron Corp., San Jose, Calif.) via an atmospheric pressure chemical ionization (APCI) interface. Both normal mass scan and collision induced dissociation (CID) experiments were performed to obtain information for chemical structure deduction.

Statistical analysis. The concentration of each putative desulfoglucosinolate was calculated based on a relationship between the chromatographic peak area and amount of sinigrin, expressed in sinigrin equivalents (ng. $\mathrm{mg}^{-1}$ dry weight) of that compound. Averages from the two analytical replicates of each sample were used as individual data points $(n=4)$ in a two-tailed $t$ test to determine if there were any significant differences between flight and ground control samples in concentrations of individual desulfoglucosinolates.

\section{Results}

\section{Growth conditions and plant development}

Brassica rapa plants developed along the expected timetable in the BPS hardware, whether in microgravity on the ISS (Fig. 1) or at 1-g in the lab at Kennedy Space Center. Environmental parameters within the chambers were recorded every 2 min throughout the mission. These data indicate that the groundbased control provided very similar temperature, humidity and light regimens to those in the spaceflight treatment (Table 1). The BPS does not have $\mathrm{CO}_{2}$ scrubbing capability, and due to the relatively small amount of leaf tissue on the $B$. rapa plants, $\mathrm{CO}_{2}$ concentrations higher than setpoint $\left(1000 \mu \mathrm{mol} \cdot \mathrm{mol}^{-1}\right)$ prevailed in both flight and ground control chambers early and late in the growth cycle (Table 1). Ethylene scrubbing by the hardware kept chamber ethylene in the $25-40 \mathrm{nmol} \cdot \mathrm{mol}^{-1}$ range (ISS atmosphere ethylene ranged from $40-70 \mathrm{nmol} \cdot \mathrm{mol}^{-1}$ ).

Hand pollination on orbit by an astronaut initiated development of siliques (Fig. 1, bottom) in the flight treatment that were comparable to those produced in the ground control. Final plant height (determined post-flight from fixed and frozen samples), silique size and number of seeds per silique were not different between the flight and ground control treatments (Table 2). Leaf chlorophyll and carbohydrate content were also not different between the two treatments (Table 3), indicating that general plant growth and development were occurring normally in microgravity.

\section{Glucosinolate accumulation}

Glucosinolates consist of $\beta$-thioglucose residue, a sulfonated oxime and a side chain. Under negative APCI mass spectrometric conditions, desulphoglucosinolates are expected to have a molecular type ion $[\mathrm{M}-\mathrm{H}]^{-}$with an even mass to charge $(\mathrm{m} / \mathrm{z})$ and probably a product ion derived from breakage of labile thio bond with $\mathrm{m} / \mathrm{z} 195$. These characteristics were used for initial screening of the HPLC peaks (Figs. 2 and 3). Results indicate that there are two detectable glucosinolates (Fig. 2C) in both ground control and space-grown tissues. The spaceflight environment did not induce any novel synthesis of glucosinolate (no difference in glucosinolate profiles shown in Fig. 2 A and B), but altered the abundance of the component eluted at retention time $8.3 \mathrm{~min}$. The mass spectrum of the peak at $8.3 \mathrm{~min}$ (Fig. 3B) was strikingly 


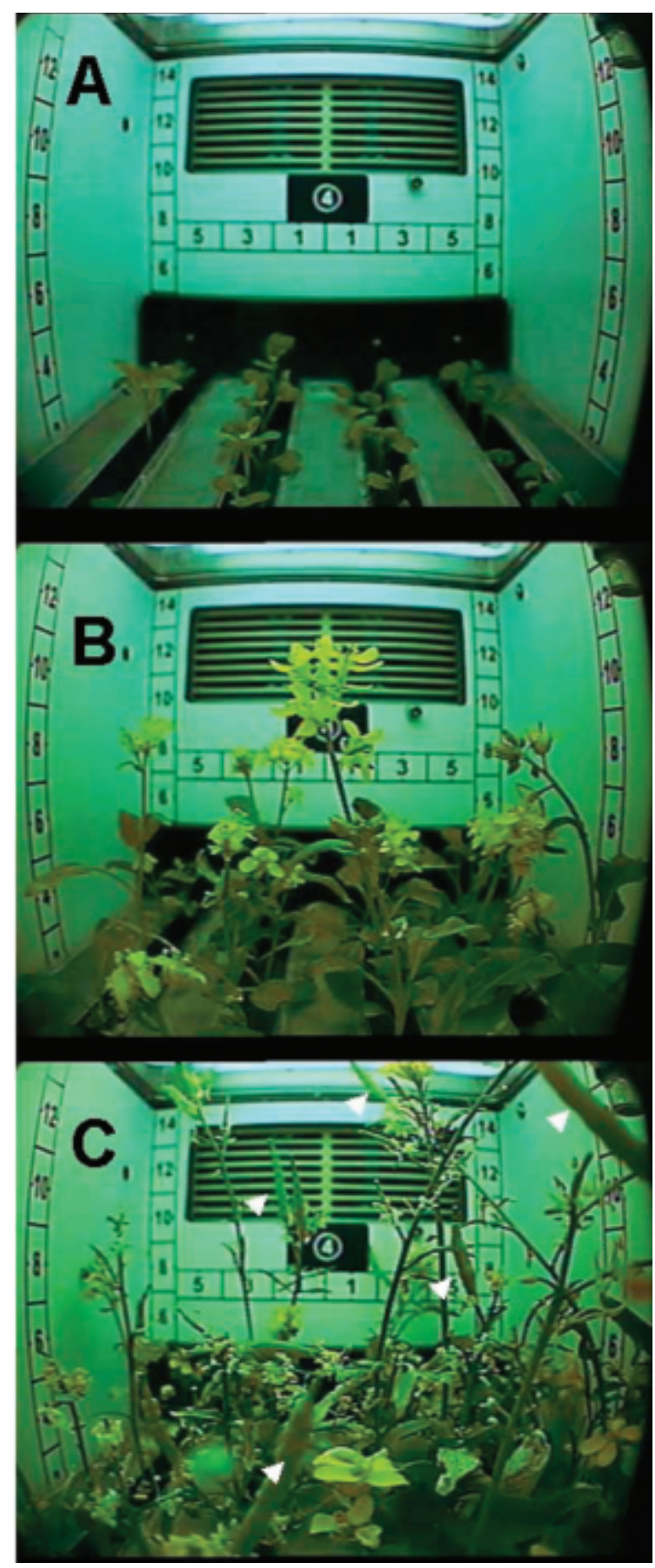

Fig. 1. View from within the Biomass Production System chamber on the International Space Station, showing B. rapa 'Astroplants' plants 8 (A), 18 $(\mathbf{B})$, and $34 \mathrm{~d}(\mathbf{C})$ after planting. Images were acquired inside the plant growth chamber at a rate of 12 images/d. Siliques, seen at different distances from the camera, are indicated by arrowheads in panel C. Scales along the side and back walls are in centimeters.

similar to that of sinigrin (5.8 min; Fig. 3A) with $14 \mathrm{u}\left(\mathrm{CH}_{2}\right)$ higher than the corresponding ions in Fig. 3A except the most abundant ion $(\Delta \mathrm{m} / \mathrm{z} 28)$ and $\mathrm{m} / \mathrm{z} 195$ belonging to a common moiety (thioglucose) of glucosinolates. Collision induced dissociation (CID) of the selected ions m/z 575 and 324 from the full mass scan of sinigrin resulted in ions $\mathrm{m} / \mathrm{z} 278$ and 195 that are the molecular type ion for sinigrin and glucosinolate signature ion, respectively. This allowed us to confidently assign m/z 575 and 324 as the
Table 1. Environmental parameters within the Biomass Production System hardware plant growth chambers in the spaceflight and ground control treatments. Lights (cool-white fluorescent) were on continuously in the chambers. Data (mean $\pm \mathrm{SD}$ ) are derived from environmental measurements taken every 2 min over $37 \mathrm{~d}$ (data were not taken for the first $2 \mathrm{~d}$ of the $39-\mathrm{d}$ growth period).

\begin{tabular}{lcc}
\hline Treatment & Flight & Ground \\
\hline Air temperature $\left({ }^{\circ} \mathrm{C}\right)$ & $24.6 \pm 0.6$ & $25.2 \pm 1.5$ \\
Root temperature $\left({ }^{\circ} \mathrm{C}\right)$ & $28.6 \pm 1.3$ & $28.2 \pm 1.8$ \\
Relative humidity $(\%)$ & $90.6 \pm 2.8$ & $90.8 \pm 3.1$ \\
Light intensity $\left(\mu \mathrm{mol} \cdot \mathrm{m}^{-2} \cdot \mathrm{s}^{-1}\right)$ & $223.1 \pm 32.4$ & $233.7 \pm 28.0$ \\
Carbon dioxide $\left(\mu \mathrm{mol} \cdot \mathrm{mol}^{-1}\right)$ & $4174 \pm 3486$ & $2600 \pm 1593$ \\
\hline
\end{tabular}

Table 2. Plant height, size of siliques, and number of seeds per silique in B. rapa 'Astroplants' grown in spaceflight on the International Space Station or in the ground control, determined from frozen and fixed samples (mean \pm SE; $n=17$, except when indicated). Differences between the flight and ground control treatments were not statistically significant.

\begin{tabular}{lrr}
\hline Treatment & \multicolumn{1}{c}{ Flight } & \multicolumn{1}{c}{ Control } \\
\hline Plant height $(\mathrm{cm})$ & $6.4 \pm 0.6$ & $7.0 \pm 0.9$ \\
Silique length $(\mathrm{mm}) \mathrm{z}$ & $20.3 \pm 2.7$ & $20.4 \pm 3.4$ \\
Seeds per silique (no.) & $6.7 \pm 1.2$ & $7.1 \pm 1.6$ \\
\hline $\mathrm{z}_{\mathrm{n}=8}$ & &
\end{tabular}

Table 3. Analysis of leaf chlorophyll and carbohydrates from B. rapa 'Astroplants' leaves frozen in flight on the International Space Station and in the ground control (mean $\pm \mathrm{SE}, \mathrm{n}=3$ ). No statistically significant differences were found between the treatments.

\begin{tabular}{lcc}
\hline Treatment & Flight & Control \\
\hline $\begin{array}{l}\text { Leaf chlorophyll }\left(\mu \mathrm{g} \cdot \mathrm{mg}^{-1}\right) \\
\text { Leaf starch [glucose equivalents }\end{array}$ & $11.4 \pm 1.0$ & $11.0 \pm 0.8$ \\
$\quad\left(\mu \mathrm{g} \cdot \mathrm{mg}^{-1}\right)$ ] & $12.6 \pm 2.3$ & $16.3 \pm 5.1$ \\
$\begin{array}{l}\text { Leaf soluble carbohydrate } \\
\quad \text { glucose equivalents }\left(\mu \mathrm{g} \cdot \mathrm{mg}^{-1}\right) \text { ] }\end{array}$ & $21.5 \pm 4.4$ & $22.1 \pm 1.7$ \\
\hline
\end{tabular}

molecular and formic acid adducts, respectively. Furthermore, CID of the selected ion $\mathrm{m} / \mathrm{z} 278$ gave rise to product ions $\mathrm{m} / \mathrm{z}$ 195 and 116 and confirmed the fragmentation pathway as shown in Fig. 5. The same analysis was performed on $\mathrm{m} / \mathrm{z} 585,338$ and 292 , producing product ions with a $\Delta \mathrm{m} / \mathrm{z}$ of $14 \mathrm{u}$ and a common ion $\mathrm{m} / \mathrm{z} 195$ (data not shown). These data strongly suggest that the component at RT $8.3 \mathrm{~min}$ has a butenyl side chain in contrast to the propenyl side chain in sinigrin. The position of the double bond was uncertain, but tentatively assigned to $\mathrm{C}-3$ based on the fact that 3-butenyl (not 2-butenyl or 1-butenyl) is commonly present in brassica and related plants (Kiddle et al., 2001). The same analytical strategy leads to tentative identification of the component at RT 5.5 min as 4-methylsulfinylbutyl glucosinolate (Fig. 5). As shown in Table 4, 3-butenyl was the predominant glucosinolate and increased by $75 \%$ in spaceflight-grown $B$. rapa stem, while 4-methylsulfinylbutyl glucosinolate, a minor component, was not significantly affected by the spaceflight environment.

\section{Seed development and storage reserve composition}

Using scanning electron microscopy (SEM), a wide range of developmental stages was observed in the embryos of the spaceflight seeds fixed on the ISS (Fig. 6A-H) while seeds from the ground control were exclusively in the pre-mature stage of development (Fig. 6I-K). A number of the immature seeds fixed on orbit showed extension of the radicle; this premature germination was not observed in the fixed samples from the ground control. Interestingly, frozen embryos examined did not show 


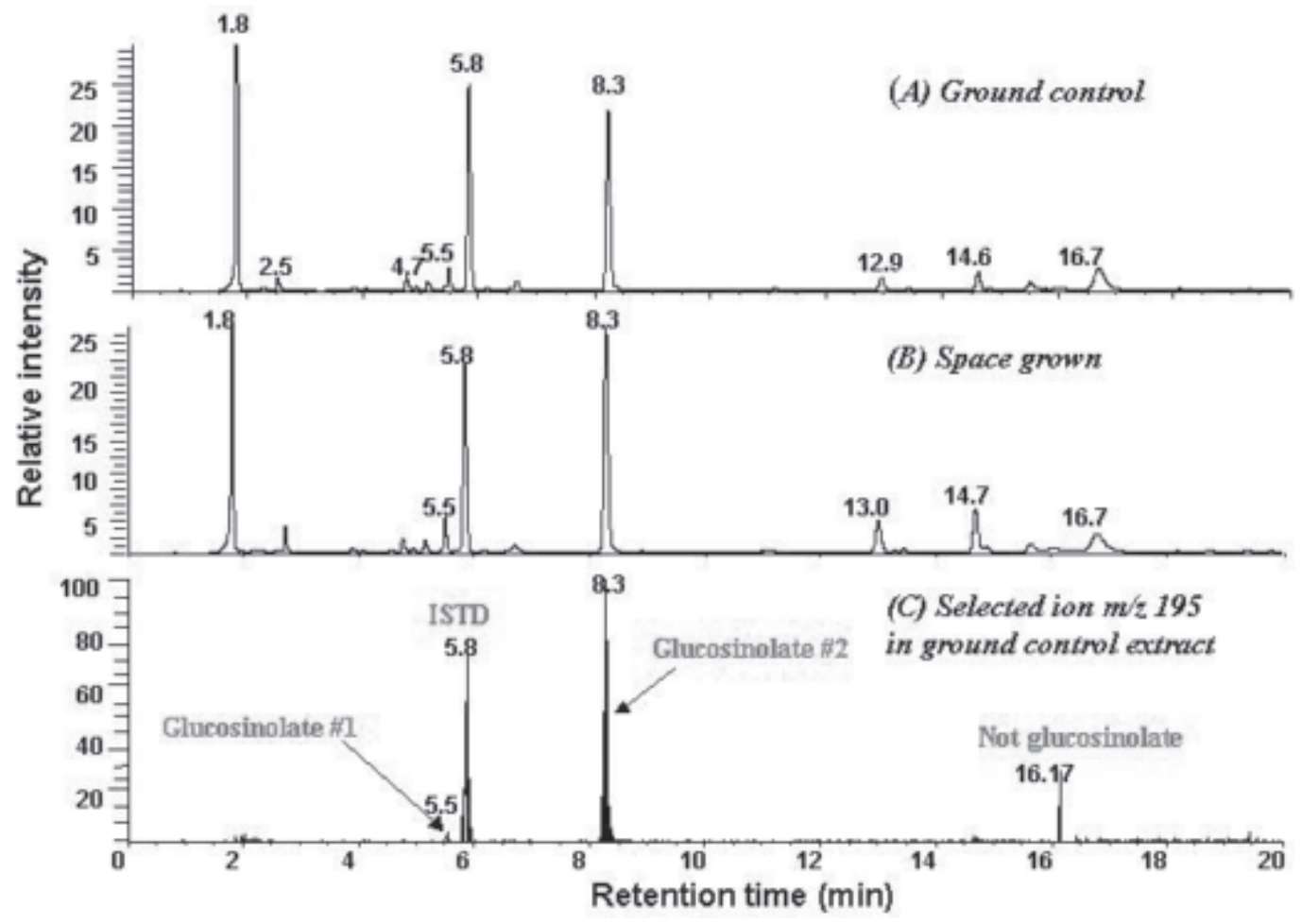

Fig. 2. HPLC/UV $227 \mathrm{~mm}$ chromatograms (A and B) and selected ion m/z 195 chromatogram $(\mathbf{C})$ of $B$. rapa 'Astroplants' extracts show no difference in glucosinolate profiles between ground control and flight grown plants, but differences in their abundance. Since m/z 195 ion is characteristic of glucosinolates, chromatogram $\mathrm{C}$ indicates that there may be three quantifiable glucosinolates in addition to sinigrin, the internal standard (ISTD). However, the mass spectrum of the peak at retention time (RT) 16.17 is very noisy and different from that of a typical glucosinolate. The peak at RT 16.17 is also not considered as a glucosinolate because there is no corresponding peak on the HPLC/UV traces.

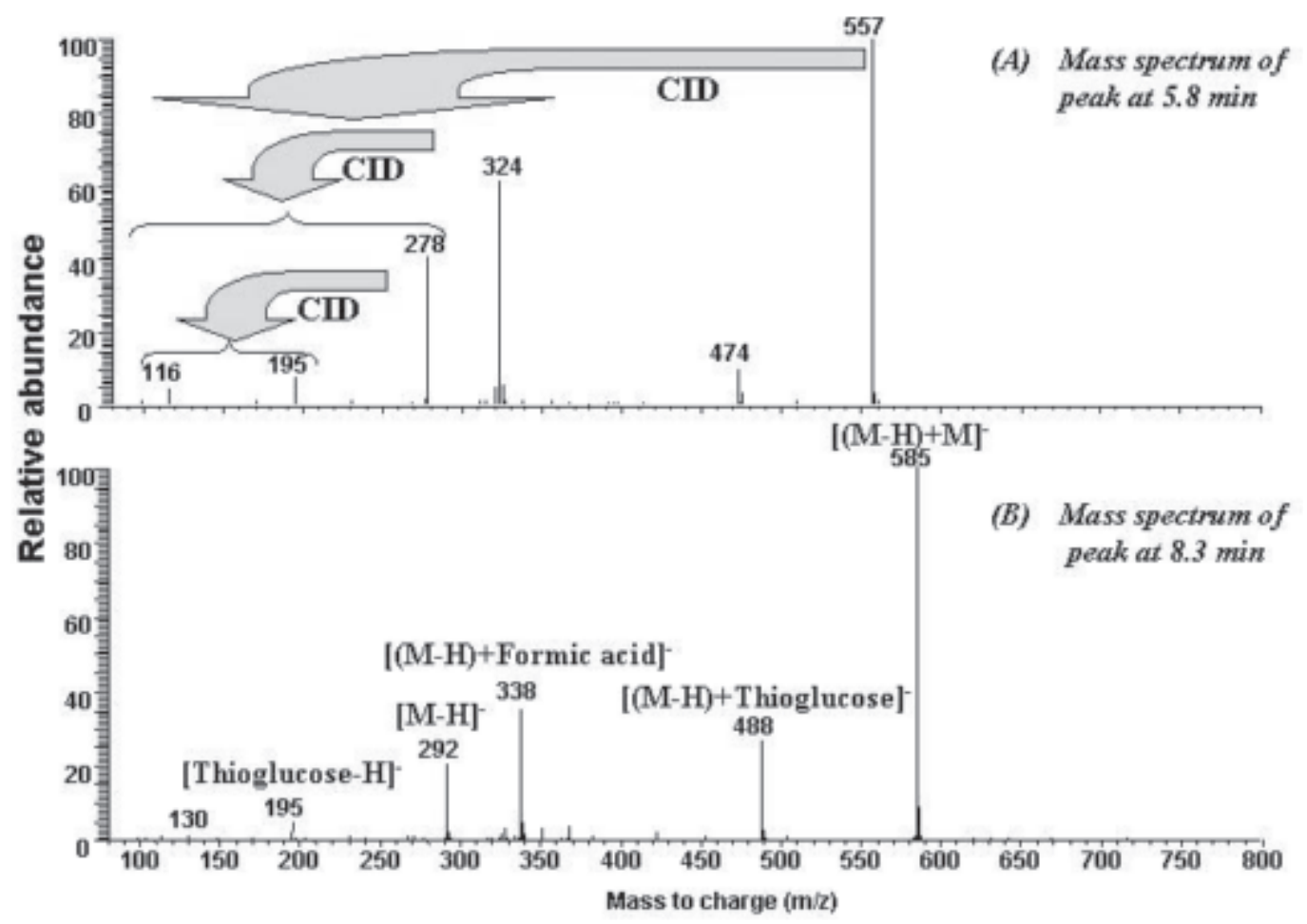

Fig. 3. Negative atmospheric pressure chemical ionization (APCI) normal scan mass spectra of peak at retention time (RT) 5.8 min (A) and at RT 8.3 min (B) and assignment of ions that were confirmed by experiments of collision induced dissociation (CID) of selected ions. 


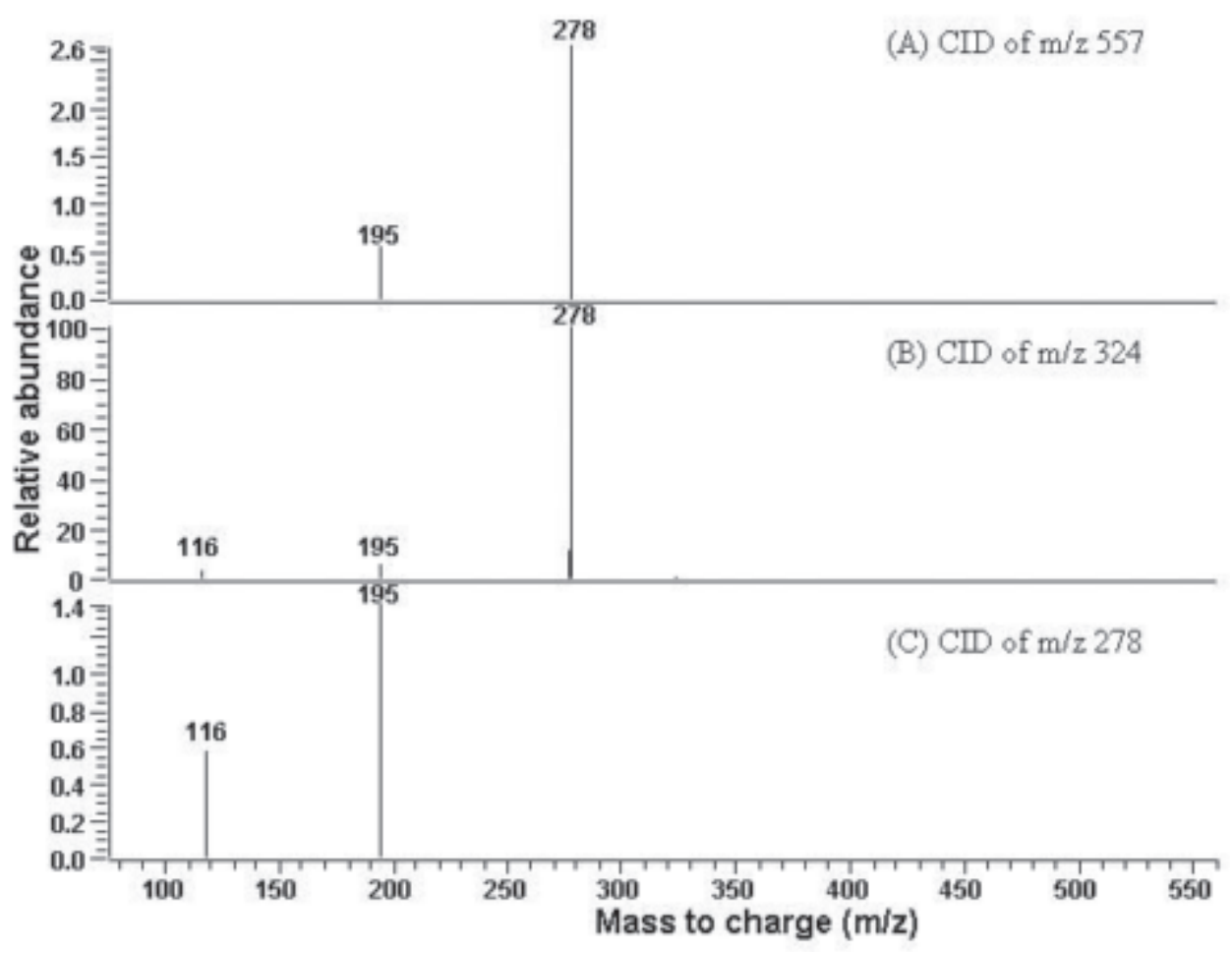

Fig. 4. Collision Induced Dissociation (CID) mass spectra of selected ions m/z 557 (A), 324 (B), and 278 (C) confirm the origin and assignment of these ions indicated in Fig. 3.

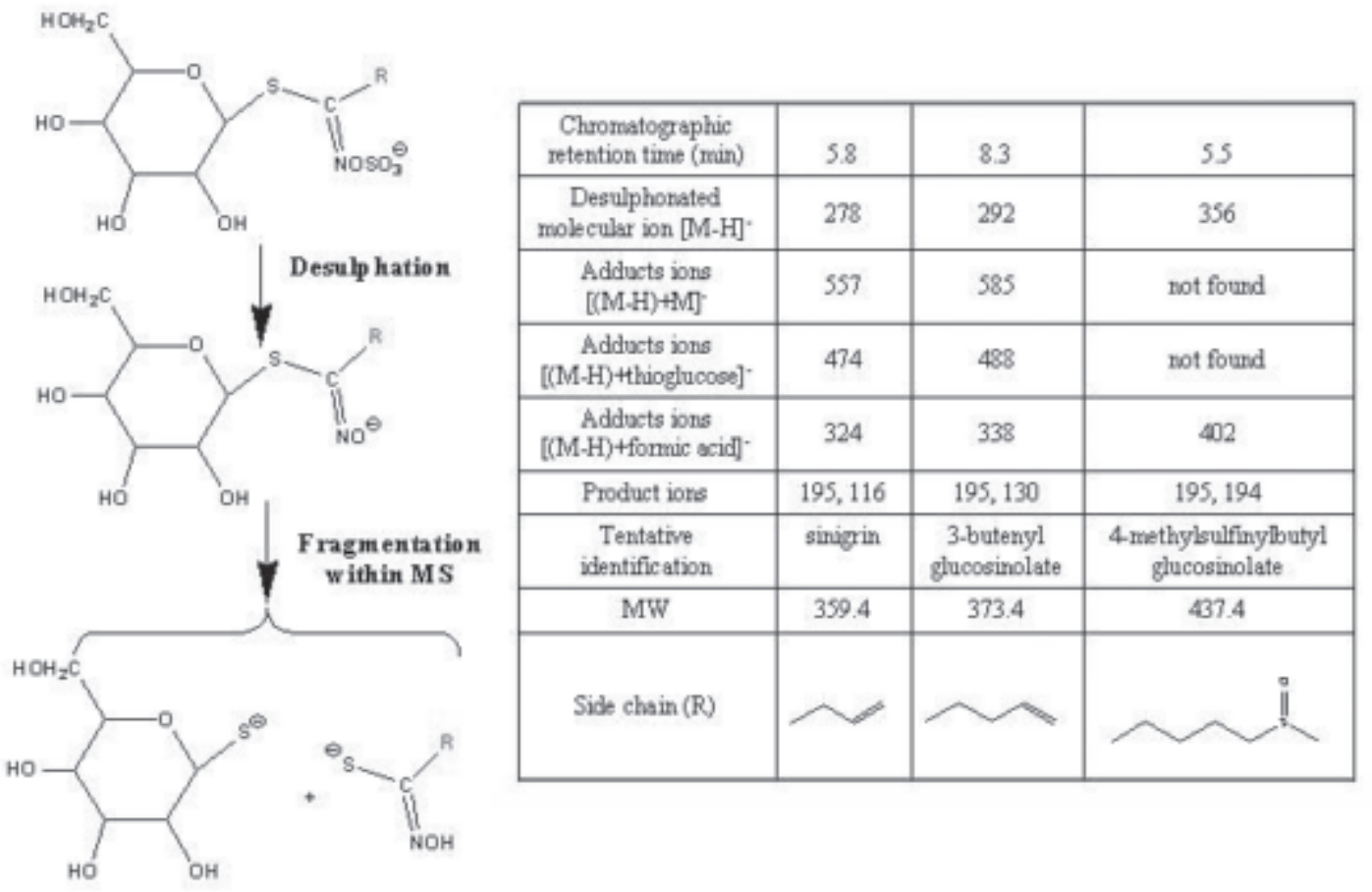

Fig. 5. Glucosinolate fragmentation pathway and ions observed.

any signs of precocious germination as was seen in the seeds fixed in flight.

Cytochemical staining showed that seeds produced on ISS exhibited variability with regard to their storage reserves. In young seeds (Fig. 6A-D), embryo cells do not contain storage reserves (Fig. 7A), while some seeds at a later developmental stage (Fig. 6E-F) contain starch grains both in cotyledon cells (Fig. 7B) and radicle cells (Fig. 7C). Only a few seeds (Fig. 6G-H) were advanced enough to show the presence of protein bodies in cotyledon cells (Fig. 7D) and radicle cells (data not shown) but those protein bodies were stained less densely compared to protein bodies in the ground control seed (Fig. 6I-K). Starch grains were also present and large vacuoles occupied large portion of the cotyledon cells, indicating that cells were at younger developmental stages 
Table 4. Stem tissue concentrations of glucosinolates identified in B. rapa 'Astroplants' grown under spaceflight and ground control conditions (mean \pm SE, $n=4)$. Treatment differences were determined statistically using a two-tailed $t$ test.

\begin{tabular}{lccc}
\hline & \multicolumn{3}{c}{$\begin{array}{l}\text { Glucosinolate concn [sinigrin } \\
\text { equivalents }\end{array}$} \\
\cline { 2 - 4 } Treatment & Flight & Ground & $P$ \\
\hline 3-butenylglucosinolate & $2210 \pm 415$ & $1250 \pm 184$ & 0.073 \\
4-methylsulfinylbutylglucosinolate & $110 \pm 53.8$ & $80.7 \pm 21.5$ & 0.59 \\
\hline
\end{tabular}
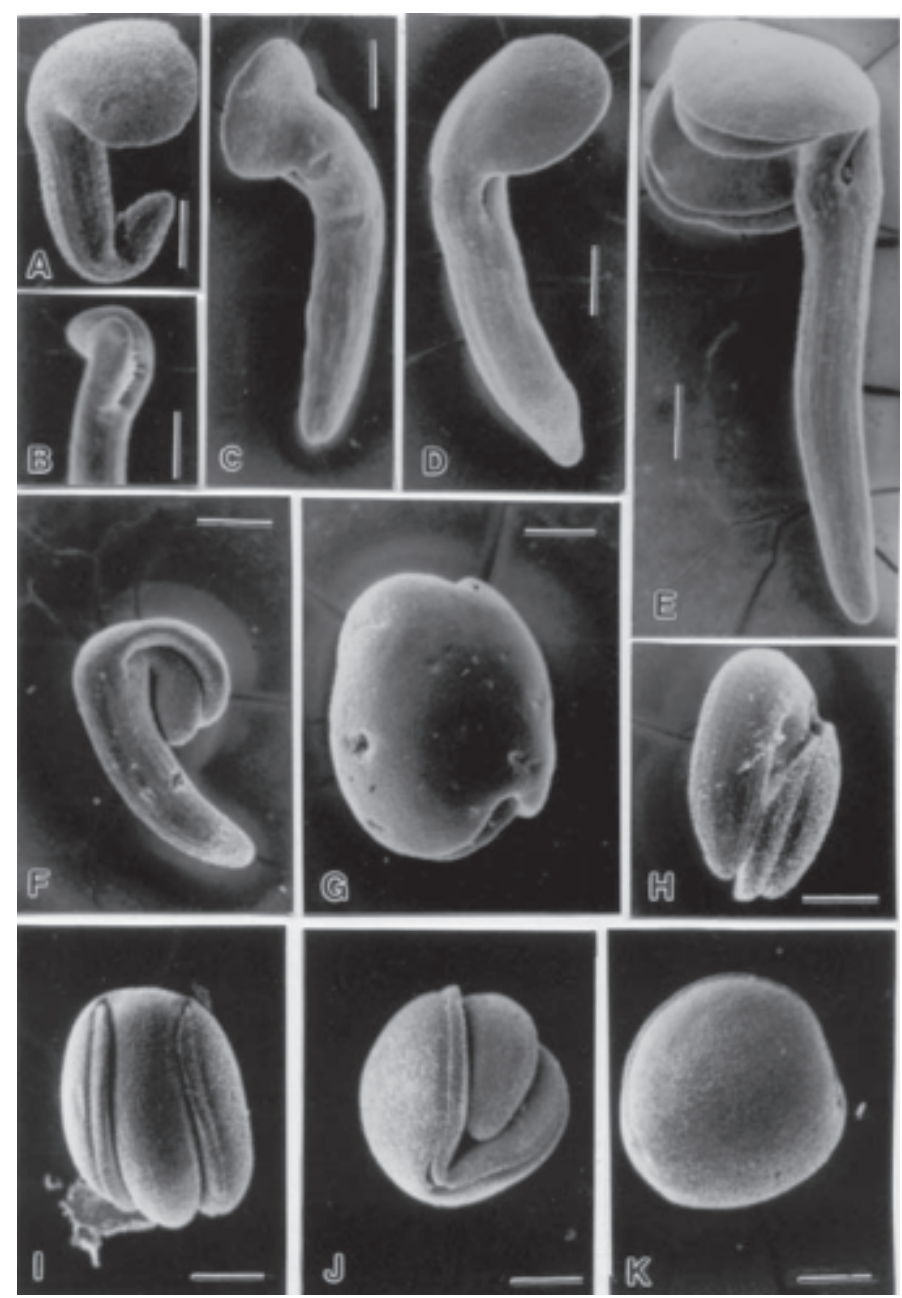

Fig. 6. Scanning electron micrographs of embryos dissected from $B$. rapa 'Astroplants' seeds produced on the International Space Station (ISS) and in the ground control. Embryos from seeds produced on ISS were at different developmental stages (A-H). Most embryos were at curled and elongated cotyledon stages $(\mathbf{A}, \mathbf{C}, \mathbf{D}, \mathbf{E}$, and $\mathbf{F})$ and a few of them at an earlier developmental stage (B). Most of those embryos have elongated radicles $(\mathbf{C}, \mathbf{D}, \mathbf{E})$. A few of embryos ( 3 of 17 embryos) developed on ISS were at the premature stage and appeared similar to the ground control seeds $(\mathbf{G})$. In contrast, all embryos from seeds produced in ground plants showed that radicles were tightly packed in folding cotyledons, indicating that seeds were at the premature stage (I, J, K); bars represent $33 \mu \mathrm{m}$.

compared to the ground control seeds. In all ground control seeds (Figs. 6I-K), both cotyledon and radicle cells were enriched with protein bodies and also contained starch grains, indicating that seeds were at the premature stage (Fig. 7E-F).

Results of the SEM and cytochemical staining studies were confirmed quantitatively through biochemical analysis of the developing seeds that had been frozen at the time of the final plant harvest, $39 \mathrm{~d}$ after planting. Weights of the lyophilized seeds produced on ISS were about half those produced in the ground based control (Table 5), in agreement with the smaller, less developed embryos observed by SEM (Fig. 6). The spaceflight seeds were visibly greener and maintained more than twice the chlorophyll concentration of the ground based controls. Starch and soluble carbohydrates were present in greater quantities in the developing seed tissue of the spaceflight material than in the ground controls, and seed protein accumulation was depressed in the spaceflight material (Table 5).

\section{Discussion}

Like our previous seed-to-seed growth of B. rapa in a wellventilated chamber on the Mir space station, the performance of B. rapa 'Astroplants' in the BPS on ISS was good. Plant dry weight, previously reported, was not statistically different in spaceflight and ground control treatments (Morrow et al., 2004). Vegetative growth was vigorous and supported normal flowering and seed initiation (Fig. 1). Analysis of plant growth, leaf tissue, number of fruits and seeds all indicated comparable performance to ground-based controls (Tables 2 and 3 ).

Despite this normal vegetative development, seed development inside the closed siliques was apparently delayed in the microgravity setting. Embryos from ISS exhibited a range of developmental stages (Figs. 6 and 7), and biochemical analysis of developing seeds frozen while still on orbit confirmed that less dry weight had accrued in the spaceflight tissue (Table 5). Spaceflight embryos had 24\% less protein than their earth-produced counterparts and starch was $117 \%$ more abundant in the seeds than in the ground-based controls (Table 5). These findings agree with cytochemical localization studies performed on mature dry seeds of B. rapa that were produced on the Mir space station (Musgrave et al., 2000), in which starch grains were retained at maturity in the spaceflight material. During normal seed development in $B$. rapa, initial storage of reserves as starch is gradually supplanted by storage in lipid and protein bodies, and mature seeds lack starch grains (Kuang et al., 2000a, 2000b). Recently we provided cytochemical localization data to show that changes in storage reserve deposition in microgravity are already manifest $13 \mathrm{~d}$ after pollination (Kuang et al., 2005), and that the differences are more pronounced in the more interior tissues, consistent with a gas exchange limitation. Similar accumulation of starch was observed during anther development in $B$. rapa in microgravity (Kuang et al., 2005). We hypothesize that $B$. rapa seed storage reserve deposition is disrupted in microgravity due to alteration of the closed gaseous microenvironment around the developing seeds (Kuang et al., 2000b; Musgrave et al., 1997). The results of our biochemical analyses on frozen developing seeds confirm the strong effect of the spaceflight environment on seed storage reserves (Table 5), and hence on the potential nutritional quality of seeds produced in microgravity. Briarty and Maher (2004) recently reported differences in storage reserve utilization in seeds of Arabidopsis thaliana (L.) Heynh. germinating in microgravity and concluded that the stagnant microenvironment around the seeds was altering metabolism.

The surprising finding of precocious germination in the immature seeds preserved by fixation (Fig. 6) (but not in those preserved by freezing) while on orbit leads us to speculate that fixative action proceeds at a different rate in microgravity. For immature seeds inside intact siliques, penetration of glutaraldehyde may have been quite slow in microgravity, where buoyancy driven convection is absent and cohesive properties of fluids dominate. 

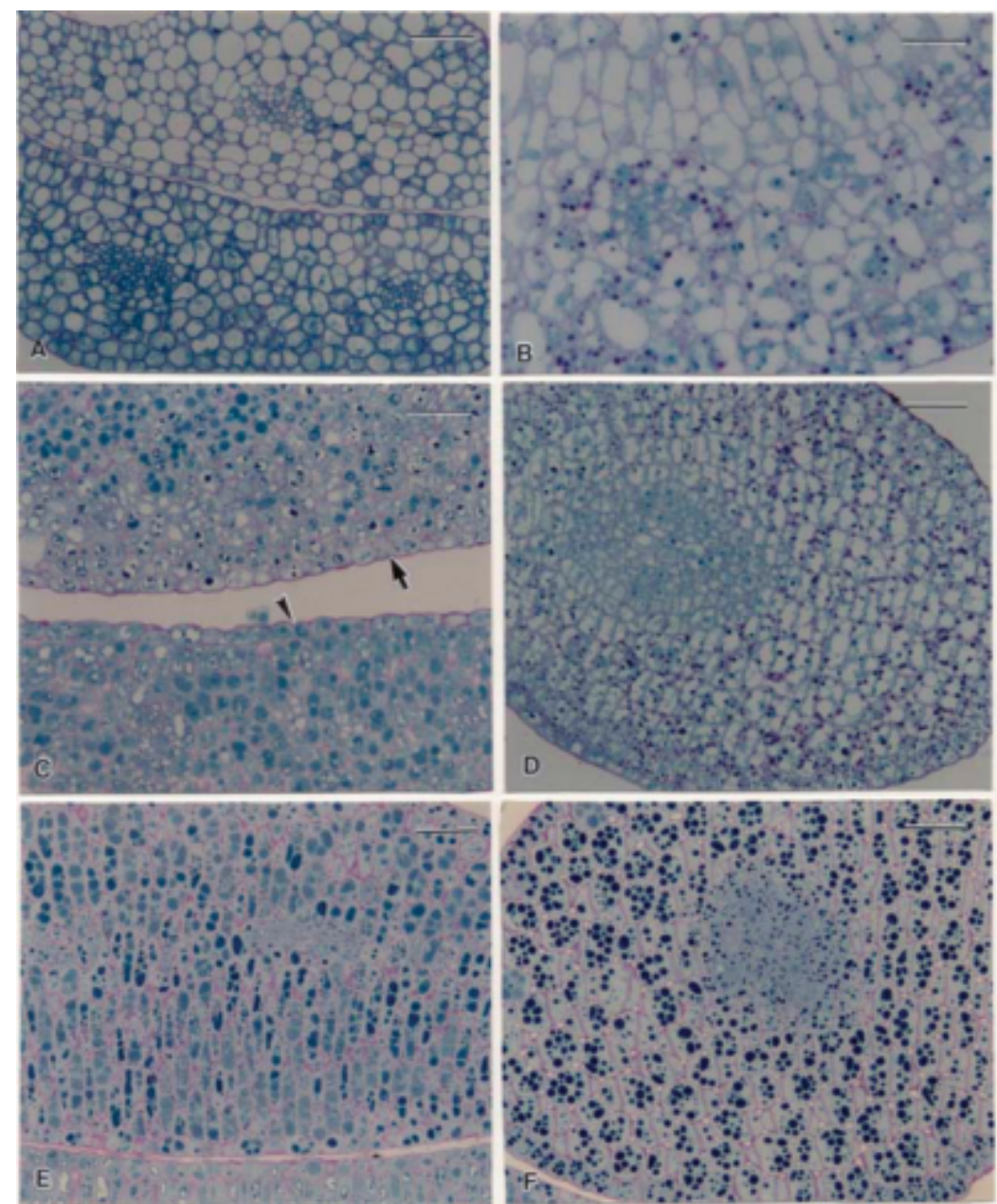

Fig. 7. Light micrographs of B. rapa 'Astroplants' embryo tissues that were stained with aniline blue black for protein and periodic-acid Schiff's reagent for carbohydrate (magenta color). (A-D) Embryo tissues of spaceflight seeds. In tissues of a young embryo (A), cells do not contain storage reserves. In an embryo at a later developmental stage, starch grains (seen here as magenta-colored granules) are present in both cotyledon cells (B) and radicle cells $(\mathbf{C})$ but no storage protein bodies (blue globular or near globular shaped objects) were observed in the spaceflight material except for lightly-staining ones in a few seeds, as shown in (D), from a cotyledon. Protein bodies are present as a major storage reserve of embryos at the latest developmental stage as shown in cotyledon $(\mathbf{E})$ and radicle $(\mathbf{F})$ tissues of ground control seeds; bars represent $10 \mu \mathrm{m}$.

Table 5. Analysis of immature B. rapa 'Astroplants' seeds frozen in flight on the International Space Station and in the ground control (mean \pm $\mathrm{SE} ; \mathrm{n}=4$, except when indicated otherwise). Treatment differences were determined statistically using a two-tailed $t$ test.

\begin{tabular}{lccl}
\hline Treatment & Flight & Control & \multicolumn{1}{c}{$P$} \\
\hline Weight $(\mathrm{mg} / \mathrm{seed})$ & $0.37 \pm 0.04$ & $0.81 \pm 0.08$ & 0.003 \\
Chlorophyll $\left(\mu \mathrm{g} \cdot \mathrm{mg}^{-1}\right)$ & $1.75 \pm 0.23$ & $0.71 \pm 0.37$ & 0.05 \\
Starch $\left[\mathrm{glucose}\left(\mu \mathrm{g} \cdot \mathrm{mg}^{-1}\right)\right.$ ] & $59.1 \pm 5.4$ & $27.2 \pm 3.0$ & 0.002 \\
Soluble carbohydrate & $107.9 \pm 35.5$ & $60.3 \pm 2.3$ & 0.23 \\
Total carbohydrate $^{\mathrm{z}}$ & $166.9 \pm 34.5$ & $87.5 \pm 1.9$ & 0.06 \\
Protein $\left(\mu \mathrm{g} \cdot \mathrm{mg}^{-1}\right)^{\mathrm{y}}$ & $298.8 \pm 23.5$ & $390.6 \pm 30.3$ & 0.075 \\
${\text { Protein }\left(\mu \mathrm{g} / \mathrm{seed}^{\mathrm{y}}\right.}^{\mathrm{y}}$ & $132.7 \pm 28.5$ & $279.9 \pm 31.1$ & 0.025 \\
\hline
\end{tabular}

${ }^{2}$ Glucose equivalents $\left(\mu \mathrm{g} \cdot \mathrm{mg}^{-1}\right)$.

$\mathrm{y}_{\mathrm{n}}=3$

The value of having the frozen material for comparison and to provide tissue for biochemical determinations was emphasized by this finding.

This is the first report of glucosinolate identification and quantification in B. rapa 'Astroplants'. That 3-butenylglucosinolate was found to be a predominant component in the stem of both ground control and space-grown plants is in agreement with previous findings (P. H. Williams, personal communication) that this glucosinolate accounts for $86 \%$ of the total glucosinolates in whole shoot tissue of rapidcycling B. rapa [CrGC-\#1; Williams and Hill (1986)], the parent material for 'Astroplants'. However, only one minor glucosinolate (4-methylsufinylbutyl glucosinolate) was detectable in this experiment in contrast to six found in the whole shoot tissue. Glucosinolates tend to occur at higher concentrations in reproductive organs (e.g., flowers, seeds) and younger tissues (e.g., meristems, new leaves) (Brown et al., 2003; Petersen et al., 2002), both of which were excluded from the present analysis of stem tissue but included in Williams' analysis (of whole plants). Interestingly, the level of 3-butenylglucosinolate was dramatically enhanced in the spaceflight material, while 4-methylsulfinylglucosinolate remained unchanged.

Because the environmental conditions in spaceflight were similar to ground control (Table 1), the large increase in glucosinolate content in the spaceflight material (Table 4) is difficult to explain as a response to standard environmental factors of light, temperature or moisture status. It is possible that distribution of water within the root zone may have differed between the two treatments because although the water delivery system pressure was the same, water distribution in the root zone in microgravity differs from that at $1-g$ (for review, see Musgrave, 2002). Plant response to $\mathrm{CO}_{2}$ enrichment in the $2000-4000 \mu \mathrm{mol} \cdot \mathrm{mol}^{-1}$ range is largely unstudied, however, the absence of difference in starch accumulation in the leaves or in leaf chlorophyll content (Table 3) suggest that the recorded differences in $\mathrm{CO}_{2}$ concentration between the flight and ground control treatment chambers (Table 1) were not physiologically significant for the plants. Our prior studies with A. thaliana in microgravity showed these foliage characteristics to be very sensitive indicators of plant status during spaceflight (Musgrave et al., 1998).

Although this is the first report of glucosinolate accumulation being affected by microgravity, similar results have been reported with another class of secondary metabolites. Levine et al. (2001) found enhanced accumulation of isoflavonoids in hypocotyl and root tissue of etiolated soybean [Glycine $\max$ (L.) Merr.] seedlings germinated in microgravity on the space shuttle, compared to ground-based controls. They concluded that the spaceflight environment had altered only the partitioning of the secondary compound, since a concomitant decrease in isoflavonoids had occurred in the spaceflight cotyledon tissues, while total plant isoflavonoid concentration was the same in spaceflight and ground control tissue.

Taking into consideration that seed development was delayed in the spaceflight treatment, we speculate that the increased glucosinolate level is the consequence of 1) greater transport of glucosinolates to the stem compared to the seed; and/or 2) reduced glucosinolate turnover as a result of reduced expression of myrosinase. Since the highest concentrations of glucosinolates are found in seeds (Brown et al., 2003), the developmental delay in the spaceflight seeds may explain the higher concentration seen in the stems. Petersen et al. (2002) found that both mature seed and siliques of $A$. thaliana share similar parent glucosinolates, and they deduced that the major amount of glucosinolates in seeds is 
synthesized de novo in siliques. However there is also evidence supporting the idea that glucosinolates in seeds are synthesized in the leaves and subsequently translocated. Glucosinolates (both intact or desulphonated) may be translocated in all organs of brassica plants, but the capacity for de novo biosynthesis varies between organs at different stages (Chen et al., 2001; Chen and Andreasson, 2001, and references cited therein).

The ability to use brassica produced in microgravity to supplement crew rations has been tested on the Mir space station using the open plant growth hardware, greenhouse Svet, to grow young plants. A series of experiments was conducted over a 10-year period, with incremental improvements in plant yield (Levinskikh et al., 2001). In taste trials of four leaf vegetables produced in microgravity in 2000, Russian cosmonauts indicated a preference for 'Red Giant' red mustard (B. juncea L.) and mizuna [B. rapa var. nipposinica (Bailey) S. Kitamura] over two other botanical varieties of B. rapa (Levinskikh et al., 2001). Given the changes found in the glucosinolate content of $B$. rapa 'Astroplants' in microgravity in this study, it would be interesting to determine if similar changes occur in these very closely related leaf vegetables, and how this might influence taste preferences.

These spaceflight-induced changes in the nutritional quality of brassica seeds and vegetative material have implications for NASA's use of plants for food and life support purposes in the agency's exploration initiative. Additionally, our finding on the presence of 4-methylsulfinylbutyl glucosinolate [a precursor of a potent Phase II anticarcinogenic inducer; Mithen (2001)] and potential increase of its level in vegetative tissue in the spaceflight environment give insight on the phytonutritional value of future space crops since the species $B$. rapa represents several horticultural crops.

\section{Literature Cited}

Branca, F., G. Li, S. Goyal, and C.F. Quiros. 2002. Survey of aliphatic glucosinolates in Sicilian wild and cultivated Brassicaceae. Phytochemistry 59:717-724.

Briarty, L.G. and E.P. Maher. 2004. Reserve utilization in seeds of Arabidopsis thaliana germinating in microgravity. Int. J. Plant Sci. 165(4):545-551.

Brown,P.D., J.G. Tokuhisa, M. Reichelt, and J.Gershenzon. 2003. Variation of glucosinolate accumulation among different organs and developmental stages of Arabidopsis thaliana. Phytochemistry 62:471-481.

Champolivier, L. and A. Merrien. 1996. Effects of water stress applied at different growth stages to Brassica napus L. var. oleifera on yield, yield components and seed quality. Eur. J. Agron. 5:153-160.

Chen, S. and E. Andreasson. 2001. Update on glucosinolate metabolism and transport. Plant Physiol. Biochem. 39:743-758.

Chen, S., B.L. Petersen, C.E. Olsen, A. Schulz, and B.A. Haliker. 2001. Long-distance phloem transport of glucosinolates in Arabidopsis. Plant Physiol. 127:194-201.

Ciska, E., B. Martyniak-Przybyszewska, and H. Kozlowska. 2000. Content of glucosinolates in cruciferous vegetables grown at the same site for two years under different climatic conditions. J. Agr. Food Chem. 48:2862-2867

Fahey, J.W., A.T. Zalcmann, and P. Talalay. 2001. The chemical diversity and distribution of glucosinolates and isothiocyanates among plants. Phytochemistry 56:5-51.

Fahey, J.W., Y. Zhang, and P. Talalay. 1997. Broccoli sprouts: An exceptionally rich source of inducers of enzymes that protect against chemical carcinogens. Proc. Natl Acad Sci USA 94(19):10367-10372.

Fang, Y., S. Yang, and G. Wu. 2002. Free radicals, antioxidants, and nutrition. Nutrition 18:872-879.

Frick, J., S.S. Nielsen, and C.A. Mitchell. 1994. Yield and seed oil content response of dwarf, rapid-cycling Brassica to nitrogen treatments, planting density, and carbon dioxide enrichment. J. Amer. Soc. Hort. Sci. 119:1137-1143.

Kiddle, G., R.N. Nennett, N.P. Botting, N.C. Davidson,A.A.B. Robertson, and R.M. Wallsgrove. 2001. High-performance liquid chromatographic separation of natural and synthetic desulphoglucosinolates and their chemical validation by UV, NMR and chemical ionization-MS methods. Phytochem. Anal. 12:226-242.

Kuang, A., A Popova, G. McClure, and M.E. Musgrave. 2005. Dynamics of storage reserve deposition during Brassica rapa L. pollen and seed development in microgravity. Intl. J. Plant Sci. 166(1):85-96.

Kuang, A., A. Popova, Y. Xiao, and M.E. Musgrave. 2000a. Pollination and embryo development in Brassica rapa L. in microgravity. Intl. J. Plant Sci. 161(2):203-211.

Kuang, A., Y. Xiao, G. McClure, and M.E. Musgrave. 2000b. Influence of microgravity on ultrastructure and storage reserves in seeds of Brassica rapa L. Ann. Bot. 85(6):851-859.

Levine, L.H., H.G. Levine, E.C. Stryjewski, V. Prima, and W.C. Piastuch. 2001. Effect of spaceflight on isoflavonoid accumulation in etiolated soybean seedlings. J. Gravitational Physiol. 8:21-27.

Levinskikh, M.A., V.N. Sytchev, I.G. Podolsky, and G.E. Bingham. 2001. Pioneering space experiments aimed at obtaining plant biomass to supplement crew food rations. Gravitational Space Biol. Bul. 15(1):53 (Abstr.).

Mansfield, S.G. and L.G. Briarty. 1996. The dynamics of seedling and cotyledon cell development in Arabidopsis thaliana during reserve mobilization. Intl. J. Plant Sci. 157(3):280-295.

Mithen, R. 2001. Glucosinolates - Biochemistry, genetics, and biological activity. Plant Growth Regulat. 34:91-103.

Morrow, R.C., J.T. Iverson, R.C. Richter, and J.J. Stadler. 2004. Biomass Production System (BPS) Technology Validation Test results. SAE Technical Paper Series 2004-01-2460.

Musgrave, M.E. 2002. Seeds in space. Seed Sci. Res. 12:1-16.

Musgrave, M.E., A. Kuang, C.S. Brown, and S.W. Matthews. 1998. Changes in Arabidopsis leaf ultrastructure, chlorophyll, and carbohydrate content during spaceflight depend on ventilation. Ann. Bot. 81:503-512.

Musgrave, M.E., A. Kuang, and S.W. Matthews. 1997. Plant reproduction during spaceflight: Importance of the gaseous environment. Planta 203(Suppl.):177-184.

Musgrave, M.E., A. Kuang, Y. Xiao, S.C. Stout, G.E. Bingham, L.G. Briarty, M.A. Levinskikh, V.N. Sychev, and I.G. Podolski. 2000. Gravity-independence of seed-to-seed cycling in Brassica rapa. Planta 210 (3):400-406.

National Research Council. 1997. Advanced technology for human support in space. Committee on advanced technology for human support in space. Aeronautics and Space Engineering Board, Natl. Academy Press, Washington, D.C.

Olabi, A.A., H.T. Lawless, J.B. Hunter, D.A. Levitsky, and B.R. Halpern. 2002. The effect of microgravity and space flight on the chemical senses. J. Food Sci. 67(2):468-478.

Pence, B.C. and T.C. Yang. 2000. Antioxidants: Radiation and stress, p. 233-251. In: H.W. Lane and D.A. Schoeller (eds.). Nutrition in spaceflight and weightlessness models. CRC Press, Boca Raton, Fla.

Pereira, F.M., E. Rosa, J.W. Fahey, K.K. Stephenson, R. Carvalho, and A. Aires. 2002. Influence of temperature and ontogeny on the levels of glucosinolates in broccoli (Brassica oleracea Var. italica) sprouts and their effect on the induction of mammalian phase 2 enzymes. J. Agr. Food Chem. 50:6239-6244.

Petersen, B.L., S. Chen, C.H. Hansen, C.E. Olsen, and B.A. Halkier. 2002. Composition and content of glucosinolates in developing Arabidopsis thaliana. Planta 214:562-571.

Porterfield, D.M., G.S. Neichitailo, A.L. Mashinski, and M.E. Musgrave. 2003. Spaceflight hardware for conducting plant growth experiments in space: The early years 1960-2000. Adv. Space Res. 31(1):183-193.

Robbelen, G. and W. Thies. 1980. Biosynthesis of seed oil and breeding for improved oil quality of rapeseed, p. 253-284. In: S. Tsunoda, K. Hinata, and C. Gomez-Campo (eds.). Brassica crops and wild allies, biology and breeding. Japan Scientific Societies Press, Tokyo.

Stout, S.C., D.M. Porterfield, L.G. Briarty, A. Kuang, and M.E. Musgrave. 2001. Evidence of rootzone hypoxia in Brassica rapa L. grown in microgravity. Intl. J. Plant Sci. 162:249-255.

Williams, P.H. and C.B. Hill. 1986. Rapid-cycling populations of Brassica. Science 232:1385-1389.

Zhang, Y. and P. Talalay. 1994. Anticarcinogenic activities of organic isothiocyanates: Chemistry and mechanisms. Cancer Res. 54:1976S-1981S. 